\title{
ESHAP versus GEMOX in Management of Relapsed or Refractory Lymphoma: A Prospective Randomized Study
}

\author{
Hamdy Zawam ${ }^{1}$, Wael Edesa ${ }^{1}$, Sherif Alrefai ${ }^{2}$, Rasha Salama ${ }^{1}$, Ahmed Abdelhafeez ${ }^{1}$ \\ ${ }^{1}$ Clinical Oncology Department, Kasr Al-Ainy Center of Clinical Oncology and Nuclear Medicine, \\ Kasr Al-Ainy School of Medicine, Cairo University, Cairo, Egypt; ${ }^{2}$ Nuclear Medicine Department, \\ Kasr Al-Ainy Center of Clinical Oncology and Nuclear Medicine, Kasr Al-Ainy School of Medicine, \\ Cairo University, Cairo, Egypt
}

Background: There is lack of evidence about the best chemotherapy regimen in treatment of relapsed/refractory Hodgkin's lymphoma (HL) and aggressive non-Hodgkin's lymphoma (NHL) lymphoma.

Aim: To compare GEMOX (gemcitabine, oxaliplatin) with ESHAP (etoposide, methylprednisolone, cytarabine arbinoside, cisplatin) regimes as $2^{\text {nd }}$ line in lymphomas.

Methods: This was a prospective randomized study that included relapsed/refractory HL and aggressive NHL patients who failed $1^{\text {st }}$ line chemotherapy. After assessment for eligibility, patients were randomized to receive GEMOX or ESHAP.

Results: The study included 41 patients, 21 of them received GEMOX and 20 received ESHAP. The response rate did not differ significantly between the GEMOX and ESHAP arms (28.6\% vs. 35\%, $\mathrm{p}=0.793)$ as well as progression free survival (8.7 months vs. 6.6 months, $\mathrm{p}=0.711$ ). By univariate analysis for the whole group, the response rate differed significantly according to disease status at relapse, time to relapse, lactate dehydrogenase, International Prognostic Index (IPI) and secondary age-adjusted IPI ( $2^{\text {ry }}$ aa-IPI). Hematological toxicity was not statistically different between the two treatment arms. GEMOX was associated with significantly less vomiting of any grade $(\mathrm{p}=0.013)$. Acute renal toxicity of any grade was significantly lower in GEMOX compared to ESHAP $(\mathrm{p}=0.003)$. In terms of peripheral neuropathy, GEMOX was associated with significantly higher all grades $(\mathrm{p}=0.0001)$.

Conclusion: The current study results suggest that the response rate and progression free survival of GEMOX and ESHAP are comparable with different toxicity profile.

Keywords: Relapsed/refractory lymphoma, GEMOX, ESHAP

Corresponding author: Ahmed Abdelhafeez, MD; Kasr Al-Ainy Center of Clinical Oncology and Nuclear Medicine, Kasr Al-Ainy School of Medicine, Cairo University, Cairo, Egypt; E-mail: hhaboda@ hotmail.com

Submitted: 27-February-2018, Revised: 15-March-2018, Accepted: 17-March-2018, Published online: 20-March-2018

\section{INTRODUCTION}

Numerous chemotherapy protocols have been used as $2^{\text {nd }}$ line treatment in relapsed or refractory aggressive non-Hodgkin's lymphoma (NHL) / Hodgkin's lymphoma (HL). An ideal regimen excludes agents that the patient has been exposed to recently, has no cross resistance to initial therapy and would allow for future stem cell collection ${ }^{1}$.

Two randomized trials have compared salvage regimens as $2^{\text {nd }}$ line. In the CORAL (Collaborative Trial in Relapsed Aggressive Lymphoma) trial, patients were randomized to R-ICE (rituximab, ifosfamide, etoposide, carboplatin) or R-DHAP (rituximab, dexamethasone, high dose Ara-C, cisplatin) ${ }^{2}$. In the second study, NCIC CTG LY12 trial, patients with aggressive lymphoma were randomized to either GDP (gemcitabine, dexamethasone, cisplatin) or DHAP ${ }^{3}$. In both trials, the response rate (RR), progression free survival (PFS) and overall survival (OS) were comparable.

Accordingly, there is lack of data regarding the best chemotherapy regimen in the $2^{\text {nd }}$ line setting. ESHAP (etoposide, methylprednisolone, cytarabine arbinoside, cisplatin) have been used as salvage chemotherapy protocol for years ${ }^{4-7}$. GEMOX (gemcitabine, oxaliplatin) is another regimen that has shown promising results in multiple phase 2 trials in patients who were not eligible for transplant ${ }^{8-12}$.

The aim of this study was to compare GEMOX to ESHAP as $2^{\text {nd }}$ line for patients with relapsed/refractory HL and aggressive NHL.

\section{METHODS}

This was a prospective randomized study including patients with relapsed/refractory HL or aggressive NHL between July 2014 and March 2016.

Eligible patients included those who relapsed after $1^{\text {st }}$ line chemotherapy or were refractory to it with an age ranging from 18 to 65 years, and an Eastern Cooperative Oncology Group (ECOG) performance status 0-2. Exclusion criteria included ECOG performance status 34, central nervous system involvement, history of another malignant disease excluding skin basal cell 
carcinoma and squamous cell carcinoma, significant cardiovascular disease with ejection fraction below 50\%, non-compliance to $1^{\text {st }}$ line treatment, and serious concomitant medical condition which may compromise participation in the study.

All patients underwent an initial evaluation, including a detailed clinical history and examination. Laboratory investigations included: complete blood count, liver function assessment (aspartate aminotransferase, alanine aminotransferase, and total bilirubin), fasting blood sugar, serum creatinine, serum uric acid, lactate dehydrogenase (LDH), hepatitis Bsurface antigen and hepatitis $C$ virus antibody. Staging was done according to Ann Arbor staging system by computerized tomography of chest, abdomen, aand pelvis, and bone marrow aspirate/biopsy. Refractory or relapse disease was defined based on Lugano criteria for response assessment ${ }^{13}$. The histologic diagnosis was documented by biopsy at relapse, while in refractory disease, no biopsy was required

Patients were randomly assigned to GEMOX or ESHAP, both given every 21 days. GEMOX regimen consisted of gemcitabine $\left(1200 \mathrm{mg} / \mathrm{m}^{2}, \mathrm{IV}\right.$, days 1 and 8$)$ and oxaliplatin $\left(120 \mathrm{mg} / \mathrm{m}^{2}\right.$, IV, day 1$)$. ESHAP regimen consisted of etoposide (40 $\mathrm{mg} / \mathrm{m}^{2}$, IV, days 1 to 4 ), methylprednisolone (500 mg, IV, day 1 ), cytarabine (2000 mg/m², IV, day 5) and cisplatin $\left(25 \mathrm{mg} / \mathrm{m}^{2}, 24\right.$ hour IV infusion, days 1 to 4 ).

Patients were assessed for response with each treatment cycle clinically and after 3 cycles by computerized tomography according to the International Working Group criteria ${ }^{13}$. Adverse events were graded according to the common terminology criteria for adverse effects (CTCAE) version 4.0. A complete blood count, serum creatinine, aspartate aminotransferase, alanine aminotransferase, and bilirubin were carried out before each chemotherapy cycle to assess for the hematological, renal and hepatic toxicity and to adjust doses of chemotherapy if necessary. Patients who achieved complete remission (CR) were referred for autologous stem cell transplant (ASCT) and those who achieved less than CR continued chemotherapy for 6 cycles.

The $1^{\text {ry }}$ end point was the $R R$, while the $2^{\text {ry }}$ end points were PFS and chemotherapy toxicity. The trial was approved by the institutional research ethics committee.

All statistics were done by SPSS software (statistical package for social science) version 17. Progression free survival was defined as the time from entry into the study until disease progression (PD) or death as a result of any cause. Survival analysis was done using the Kaplan-Meier method and compared by log-rank test for significance. All reported $\mathrm{p}$ values were two-sided, and $\mathrm{p}$ value $<0.05$ was considered significant.

\section{RESULTS}

Forty-one patients were included in the current study, 21 in the GEMOX arm and 20 in the ESHAP arm, and the majority had an advanced stage (III/IV) (81\% and $80 \%$, respectively).
Table 1. Patients' characteristics

\begin{tabular}{|c|c|c|c|}
\hline \multirow[t]{2}{*}{ Characteristic } & $\begin{array}{l}\text { GEMOX } \\
(\mathrm{n}=21)\end{array}$ & $\begin{array}{l}\begin{array}{l}\text { ESHAP } \\
(n=20)\end{array} \\
\end{array}$ & \multirow[t]{2}{*}{$\begin{array}{l}P \\
\text { value }\end{array}$} \\
\hline & $\mathrm{n}(\%)$ & $\mathrm{n}(\%)$ & \\
\hline \multicolumn{4}{|l|}{ Age (years) } \\
\hline$<60$ & $17(81)$ & $18(90)$ & \multirow[t]{2}{*}{0.35} \\
\hline$>60$ & $4(19)$ & $2(10)$ & \\
\hline Median (range) & $40(26-65)$ & $43(20-63)$ & 0.99 \\
\hline \multicolumn{4}{|l|}{ Gender } \\
\hline Male & $10(52.4)$ & $10(50)$ & \multirow[t]{2}{*}{0.56} \\
\hline Female & $11(47.6)$ & $10(50)$ & \\
\hline \multicolumn{4}{|l|}{ Pathology } \\
\hline Hodgkin's lymphoma & $6(28.6)$ & $5(25)$ & \multirow[t]{3}{*}{0.33} \\
\hline DLBCL & $15(71.4)$ & $13(65)$ & \\
\hline T-cell lymphoma & 0 & $2(10)$ & \\
\hline \multicolumn{4}{|l|}{ Prior chemotherapy } \\
\hline ABVD & $6(28.6)$ & $5(25)$ & \multirow[t]{4}{*}{0.39} \\
\hline $\mathrm{CHOP}$ & $14(66.6)$ & $14(70)$ & \\
\hline EPOCH & $1(4.8)$ & 0 & \\
\hline HyperCVAD & 0 & $1(5)$ & \\
\hline \multicolumn{4}{|l|}{ Number of cycles } \\
\hline Median (range) & $4(3-8)$ & $6(2-8)$ & 0.84 \\
\hline Prior $1^{\text {st }}$ line rituximab & $3(14.3)$ & $2(15)$ & 0.54 \\
\hline Hepatitis $\mathrm{C}$ virus positive & $3(14.3)$ & $5(25)$ & 0.31 \\
\hline \multicolumn{4}{|c|}{ Ann Arbor Stage at relapse } \\
\hline II & $4(19)$ & $4(20)$ & \multirow[t]{3}{*}{0.97} \\
\hline III & $7(33.3)$ & $6(30)$ & \\
\hline IV & $10(47.7)$ & $10(50)$ & \\
\hline \multicolumn{4}{|l|}{ Lactate dehydrogenase } \\
\hline Above normal & $10(47.7)$ & $7(35)$ & \multirow[t]{2}{*}{0.55} \\
\hline Normal & $3(14.3)$ & $2(10)$ & \\
\hline \multicolumn{4}{|c|}{ ECOG performance scale } \\
\hline $0-1$ & $14(66.3)$ & $10(50)$ & 0.31 \\
\hline $2-3$ & $7(33.7)$ & $10(50)$ & \\
\hline Extranodal involvement & $8(38)$ & $9(45)$ & 0.8 \\
\hline$\geq 1$ extranodal site & $2(9.5)$ & $2(10)$ & 0.97 \\
\hline Bone marrow involved & $5(23)$ & $4(20)$ & 0.85 \\
\hline B symptoms & $9(42.9)$ & $7(35)$ & 0.42 \\
\hline \multicolumn{4}{|l|}{ Largest tumor diameter } \\
\hline$\leq 10 \mathrm{~cm}$ & $17(81)$ & $14(70)$ & \multirow[t]{2}{*}{0.32} \\
\hline$>10 \mathrm{~cm}$ & $4(19)$ & $6(30)$ & \\
\hline \multicolumn{4}{|l|}{ Disease status } \\
\hline Relapsed & $10(47.6)$ & $7(35)$ & 0.30 \\
\hline Refractory & $11(52.4)$ & $13(65)$ & \\
\hline Time to relapse & & & \\
\hline$>12$ months & $7(33.3)$ & $6(30)$ & 0.54 \\
\hline$\leq 12$ months & $14(66.7)$ & $14(70)$ & \\
\hline $2^{\text {ry }}$ aa-IPI for DLBCL & & & \\
\hline Low $(0-1)$ & $3(14.3)$ & $3(15)$ & 0.95 \\
\hline Intermediate (2) & $8(38)$ & $6(30)$ & \\
\hline High (3) & $4(19)$ & $4(20)$ & \\
\hline IPI for DLBCL at relapse & & & \\
\hline Low $(0-1)$ & $2(9.5)$ & $3(15)$ & 0.61 \\
\hline Intermediate (2-3) & $8(38)$ & $7(35)$ & \\
\hline High (4-5) & $5(23.8)$ & $3(15)$ & \\
\hline Diabetes & & & \\
\hline Yes & $3(14.3)$ & $3(15)$ & 0.64 \\
\hline No & $18(85.7)$ & $17(85)$ & \\
\hline $\begin{array}{l}\text { GEMOX: Gemcitabine, } \\
\text { methylprednisolone, cytarabine } \\
\text { large B-cell lymphoma; ABV } \\
\text { dactinomycin; CHOP: Cyc } \\
\text { prednisone; EPOCH: Etoposide } \\
\text { adriamycin; HyperCVAD: Cy } \\
\text { dexamethasone, methotrexate, } \\
\text { Oncology Group), aa-IPI: age-a }\end{array}$ & $\begin{array}{l}\text { oxaliplatin; } \\
\text { arbinoside, cis } \\
\text { D: Adriamycin } \\
\text { lophosphamide, } \\
\text { prednisone, on } \\
\text { clophosphamide } \\
\text { cytarabine; EC } \\
\text { justed Internatic }\end{array}$ & $\begin{array}{l}\text { ESHAP: } \\
\text { platin; DLBCI } \\
\text { bleomycin, v } \\
\text { adriamycin, } \\
\text { covin, cyclopho } \\
\text { vincristine, a } \\
\text { OG: Eastern C } \\
\text { nal Prognostic I }\end{array}$ & $\begin{array}{l}\text { etoposide, } \\
\text { L: Diffuse } \\
\text { vinblastine, } \\
\text { oncovin, } \\
\text { osphamide, } \\
\text { driamycin, } \\
\text { ooperative } \\
\text { Index . }\end{array}$ \\
\hline
\end{tabular}


Almost half $(52.4 \%)$ in GEMOX had refractory disease, while it represented two thirds $(65 \%)$ in ESHAP arm. Patients' characteristics were not significantly different between the 2 treatment arms (table 1).

During the study period, 63 cycles of GEMOX were administered with a median of 3 cycles (range: 1-6) compared to 68 cycles of ESHAP with a median of 3 cycles (range: 1-6). Eight (38\%) patients in the GEMOX arm experienced treatment delay compared to $9(45 \%)$ in the ESHAP with total number of 80 days and a median of 7 days in the GEMOX arm compared to 73 days and a median of 8.5 days in the ESHAP arm. The main cause of chemotherapy delay was grade 3 neutropenia in 4 (19\%) patients in the GEMOX arm and $5(25 \%)$ patients in the ESHAP arm. One patient in each arm had also grade 3 thrombocytopenia and grade 3 nausea and vomiting. The $2^{\text {nd }}$ common cause of treatment delay was non-compliance in $2(14.2 \%$ and $10 \%)$ patients in each of the treatment arms. Other causes in the ESHAP arm were grade 3 nausea and vomiting in 2 patients and grade 3 anemia in 1 patient. Other causes in the GEMOX arm were grade 3 hepatic toxicity in 1 patient and grade 3 peripheral neuropathy in another 1 . Two patients in the GEMOX arm had 25\% dose reduction due to persistent grade 3 neutropenia and grade 3 hepatic toxicity while only 1 patient in ESHAP arm had $25 \%$ dose reduction due to persistent grade 3 neutropenia.

The median follow up was 9.8 months (range 2-21.7 months). The RR was $28.6 \%$ in the GEMOX arm vs. $35 \%$ in the ESHAP with no significant difference. Progression free survival did not differ significantly between both arms (8.7 months [95\% CI=3.6-10.4] for GEMOX vs. 6.6 months [95\%CI=2.6-10.9] for ESHAP; $\mathrm{p}=0.711)$ (table 2, figure 1).

Table 2. Response to GEMOX and ESHAP

\begin{tabular}{|c|c|c|c|}
\hline \multirow[t]{2}{*}{ Response } & $\begin{array}{l}\text { GEMOX } \\
n=21\end{array}$ & $\begin{array}{l}\text { ESHAP } \\
n=20\end{array}$ & \multirow[t]{2}{*}{$\begin{array}{l}P \\
\text { value }\end{array}$} \\
\hline & n (\%) & n (\%) & \\
\hline Complete response & $2(9.6)$ & $2(10)$ & \multirow[t]{4}{*}{0.79} \\
\hline Partial response & $4(19)$ & $5(25)$ & \\
\hline Stable disease & $3(14.2)$ & $2(10)$ & \\
\hline Disease progression & $12(57.2)$ & $11(55)$ & \\
\hline
\end{tabular}

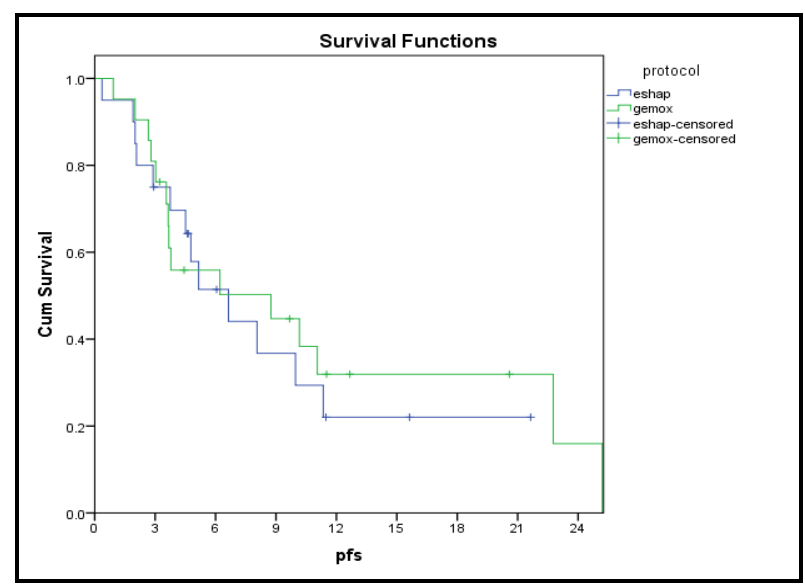

Figure 1. Progression free survival curves of GEMOX and ESHAP arms
Among the whole patients' set, disease status at relapse, time to relapse, LDH, IPI and $2^{\text {ry }}$ age adjusted IPI (aa-IPI) had significant impact on response (table 3 ).

Table 3. Univariate analysis for factors affecting response

\begin{tabular}{|c|c|c|c|}
\hline Variable & $\begin{array}{l}\text { CR/PR } \\
(n=13) \\
n(\%)\end{array}$ & $\begin{array}{l}\begin{array}{l}\text { SD/DP } \\
(n=28)\end{array} \\
\mathbf{n}(\%) \\
\end{array}$ & $\begin{array}{l}\mathbf{P} \\
\text { value }\end{array}$ \\
\hline \multicolumn{4}{|l|}{ Age (years) } \\
\hline$<60$ & $11(84.6)$ & $24(85.7)$ & \multirow[t]{2}{*}{0.62} \\
\hline$>60$ & $2(15.4)$ & $4(14.3)$ & \\
\hline Prior $1^{\text {st }}$ line Rituximab & $2(15.3)$ & $3(10.7)$ & 0.51 \\
\hline \multicolumn{4}{|l|}{ Ann Arbor Stage at relapse } \\
\hline II & $4(19)$ & $4(20)$ & \multirow[t]{2}{*}{0.97} \\
\hline III-IV & $9(69.3)$ & $24(85.7)$ & \\
\hline \multicolumn{4}{|l|}{ Lactate dehydrogenase } \\
\hline Above normal & $4(30)$ & $13(46.5)$ & \multirow[t]{2}{*}{0.02} \\
\hline Normal & $3(23$ & $2(7)$ & \\
\hline \multicolumn{4}{|l|}{ ECOG performance scale } \\
\hline$\underline{0-1}$ & $9(69.2)$ & $15(53.5)$ & \multirow[t]{2}{*}{0.55} \\
\hline $2-3$ & $4(30.8)$ & $13(46.5)$ & \\
\hline Extranodal involvement & $3(23)$ & $14(50)$ & 0.64 \\
\hline$\geq 1$ extranodal site & $1(7.6)$ & $4(14.7)$ & 0.81 \\
\hline Bone marrow involvement & $2(15.3)$ & $7(25)$ & 0.35 \\
\hline B symptoms & $4(30.6)$ & $12(42.8)$ & 0.35 \\
\hline \multicolumn{4}{|l|}{ largest tumor diameter } \\
\hline$\leqq 10 \mathrm{~cm}$ & $1(7.6)$ & $9(32.1)$ & \multirow[t]{2}{*}{0.09} \\
\hline$>10 \mathrm{~cm}$ & $12(92.4)$ & $19(67.9)$ & \\
\hline \multicolumn{4}{|l|}{ Disease status } \\
\hline Relapsed & $10(76.9)$ & $7(33.3)$ & \multirow[t]{2}{*}{0.30} \\
\hline Refractory & $3(23.1)$ & $21(66.7)$ & \\
\hline \multicolumn{4}{|l|}{$\begin{array}{l}\text { Time to relapse after } \\
\text { diagnosis }\end{array}$} \\
\hline$>12$ months & $7(53.8)$ & $6(21.4)$ & \multirow[t]{2}{*}{0.04} \\
\hline$\leq 12$ months & $6(46.2)$ & $22(78.6)$ & \\
\hline \multicolumn{4}{|l|}{$2^{\text {ry }}$ aa-IPI (DLBCL patients) } \\
\hline Low $(0-1)$ & $3(23)$ & $3(10.8)$ & \multirow[t]{3}{*}{0.03} \\
\hline Intermediate (2) & $5(38.5)$ & $9(32)$ & \\
\hline High (3) & 0 & $8(28.6)$ & \\
\hline \multicolumn{4}{|l|}{$\begin{array}{l}\text { IPI at relapse (DLBCL } \\
\text { patients) }\end{array}$} \\
\hline Low $(0-1)$ & $3(23)$ & $2(7.5)$ & \multirow[t]{3}{*}{0.03} \\
\hline Intermediate (2-3) & $5(38.5)$ & $10(35.7)$ & \\
\hline High (4-5) & 0 & $8(28.6)$ & \\
\hline
\end{tabular}

CR/PR: Complete response/partial response; SD/DP: Stable disease/ disease progression; ECOG: Eastern Cooperative Oncology Group; aa-IPI: age-adjusted International Prognostic Index: IPI: International Prognostic Index; DLBCL: Diffuse large B-cell lymphoma.

The most common hematological toxicities in both arms were anemia, neutropenia and thrombocytopenia respectively, with no statistically significant difference between them. Platelet transfusion was given to 1 patient in the GEMOX arm due to grade 4 thrombocytopenia and hematuria. Febrile neutropenia was observed in 3 patients in the GEMOX arm and 6 in the ESHAP arm with no toxicity related deaths reported during the study period.

The most common non-hematological toxicities in both arms were nausea and vomiting. The prevalence of nausea did not differ significantly; however, GEMOX was associated with significantly less vomiting of any grade $(\mathrm{p}=0.013)$. Acute renal toxicity of any grade was significantly lower in GEMOX $(\mathrm{P}=0.003)$. In terms of 
peripheral neuropathy, GEMOX was associated with significantly higher all grades $(\mathrm{p}=0.0001)$. Toxicities are summarized in table 4.

Table 4. Toxicity profile of the two treatment groups

\begin{tabular}{|c|c|c|c|}
\hline \multirow[t]{2}{*}{ Toxicity } & $\begin{array}{l}\text { GEMOX } \\
(\mathbf{n}=\mathbf{2 1})\end{array}$ & $\begin{array}{l}\text { ESHAP } \\
(\mathbf{n}=\mathbf{2 0})\end{array}$ & $\begin{array}{l}\mathbf{P} \\
\text { value }\end{array}$ \\
\hline & n(\%) & $\mathrm{n}(\%)$ & \\
\hline \multicolumn{4}{|l|}{ Hematological toxicity } \\
\hline \multicolumn{4}{|l|}{ Anemia } \\
\hline Any grade & $17(80.9)$ & $14(70)$ & 0.62 \\
\hline Grade1-2 & $13(61.9)$ & $9(45)$ & \multirow[t]{2}{*}{0.53} \\
\hline Grade 3-4 & $4(19)$ & $5(25)$ & \\
\hline \multicolumn{4}{|l|}{ Neutropenia } \\
\hline Any grade & $10(47.6)$ & $13(65)$ & 0.21 \\
\hline Grade1-2 & $6(28.5)$ & $8(40)$ & \multirow{2}{*}{0.47} \\
\hline Grade3-4 & $4(19)$ & $5(25)$ & \\
\hline \multicolumn{4}{|l|}{ Thrombocytopenia } \\
\hline Any grade & $7(33.3)$ & $5(25)$ & 0.40 \\
\hline Grade1-2 & $5(23.8)$ & $3(15)$ & \multirow{2}{*}{0.56} \\
\hline Grade3-4 & $2(9.5)$ & $2(10)$ & \\
\hline Febrile neutropenia & $3(14.2)$ & $6(30)$ & 0.2 \\
\hline \multicolumn{4}{|l|}{ Non-hematological } \\
\hline \multicolumn{4}{|l|}{ Acute renal toxicity } \\
\hline Any grade & 0 & $6(30)$ & 0.003 \\
\hline Grade1-2 & 0 & $6(30)$ & \multirow[t]{2}{*}{0.003} \\
\hline Grade 3-4 & 0 & 0 & \\
\hline \multicolumn{4}{|l|}{ Hepatic toxicity } \\
\hline Any grade & $7(33.3)$ & $3(15)$ & 0.15 \\
\hline Grade1-2 & $6(28.5)$ & $3(15)$ & \multirow[t]{2}{*}{0.26} \\
\hline Grade 3-4 & $1(4.7)$ & 0 & \\
\hline \multicolumn{4}{|l|}{ Diarrhea } \\
\hline Any grade & $5(23.8)$ & $3(15)$ & \multirow{3}{*}{$\begin{array}{l}0.3 \\
0.48\end{array}$} \\
\hline Grade1-2 & $4(19)$ & $3(15)$ & \\
\hline Grade3-4 & $1(4.8)$ & 0 & \\
\hline \multicolumn{4}{|l|}{ Vomiting } \\
\hline Any grade & $11(52.3)$ & $17(85)$ & 0.01 \\
\hline Grade1-2 & $10(47.6)$ & $15(75)$ & \multirow[t]{2}{*}{0.01} \\
\hline Grade3-4 & $1(4.7)$ & $2(10)$ & \\
\hline \multicolumn{4}{|l|}{ Nausea } \\
\hline Any grade & $14(66.6)$ & $18(90)$ & 0.07 \\
\hline Grade1-2 & $13(61.9)$ & $15(75)$ & \multirow[t]{2}{*}{0.59} \\
\hline Grade3-4 & $1(4.7)$ & $3(15)$ & \\
\hline \multicolumn{4}{|l|}{ Mucositis } \\
\hline Any grade & $8(38)$ & $9(45)$ & 0.44 \\
\hline Grade 1-2 & $7(33.3)$ & $8(40)$ & \multirow{2}{*}{0.84} \\
\hline Grade3-4 & $1(4.7)$ & $1(5)$ & \\
\hline \multicolumn{4}{|l|}{ Peripheral neuropathy } \\
\hline Any grade & $18(85.7)$ & $1(5)$ & 0.001 \\
\hline Grade1-2 & $17(80.9)$ & $1(5)$ & \multirow{2}{*}{0.001} \\
\hline Grade3-4 & $1(4.8)$ & 0 & \\
\hline $\begin{array}{l}\text { Laryngo-pharyngeal } \\
\text { dysesthesia }\end{array}$ & $14(66.6)$ & 0 & 0.001 \\
\hline
\end{tabular}

At the time of analysis (May 2016), 1 of the 2 patients in the GEMOX arm who achieved CR was referred for ASCT and the other developed PD. Similarly, 1 of the 2 patients who achieved CR in the ESHAP arm was referred for ASCT and the other lost to follow up.

\section{DISCUSSION}

Treatment of relapsed/refractory aggressive NHL and HL represents a challenge for both patients and clinicians, since more than half of these patients cannot be cured even with the addition of rituximab 14, 15 . Autologous stem cell transplantation is the standard of care in chemotherapy-sensitive relapsed/refractory aggressive NHL and HL 16, 17 .

An ideal salvage therapy regimen for use prior to ASCT should have a high response rate, low hematologic and non-hematologic toxicity, and should not impair the harvesting of stem cells ${ }^{18}$. There is lack of evidence regarding which the best chemotherapy that can be used in the $2^{\text {nd }}$ line setting. GEMOX regimen has shown promising results in multiple phase 2 trials in patients who were not eligible for transplant. Therefore, in our study we compared GEMOX against the standard ESHAP regimen ${ }^{8-12}$.

In the majority of studies testing ESHAP as a $2^{\text {nd }}$ line, the overall RR ranged between $53 \%$ and $73 \%$ (CR $37-50 \%)^{4-7}$. On the other hand, R-GEMOX overall RR ranged between $43 \%$ and $83 \%$ (CR 34-50\%) ${ }^{9-11}$. The overall RR to GEMOX without rituximab in DLBCL was $57 \%$, with $30 \% \mathrm{CR}$ achievement ${ }^{12}$. For HL, a study that included 24 patients reported $71 \%$ RR $(38 \% \mathrm{CR})^{8}$.

In the current study, there was no statistically significant difference in RR between GEMOX and ESHAP (28.6\% vs. $35 \%$ respectively and CR was equal in both arms (9.6\% vs. $10 \%$ respectively). These results are inferior when compared to the international figures. This could be attributed to the high percentage of $1^{\text {ry }}$ refractory disease in our study, the fact that only one third of patients had a time to relapse $>12$ months; and unfortunately, rituximab was not given due to logistic and financial reasons.

In the present study, factors affecting RR were disease status at relapse, time to relapse after $1^{\text {st }}$ line, IPI at relapse, $\mathrm{LDH}$ and $2^{\text {ry }}$ aa-IPI. These results are consistent with previously published studies ${ }^{2,19-22}$.

As regards to the toxicity profile of GEMOX and ESHAP, the hematologic toxicity rates were similar in both arms. In contrast, the non-hematologic toxicities were different between both groups. Renal toxicity and vomiting were less with GEMOX while neurotoxicity was lower in ESHAP. Thus GEMOX may be considered in frail patients with renal impairment.

Successful stem cell collection is a fundamental prerequisite for salvage chemotherapy regimens. However, due to the limited number of patients who received GEMOX and referred for ASCT, this point cannot be answered in our study. Quality of life was not assessed in the current study. GEMOX could be more convenient because this regimen is typically administered on an outpatient basis, compared to 5 days admission in ESHAP regimen. However, the price of individual drugs in GEMOX is more costly in comparison to ESHAP, plus the hospitalization costs.

Limitations of this study were the small sample size and the lack of response assessment by functional imaging. Other limitation was that, in DLBCL patients, cell of origin studies were not performed. The cell of 
origin remains a major and independent factor in relapsed/ refractory DLBCL, with a better response to RDHAP in GCB-like DLBCL ${ }^{23}$.

\section{Conclusion}

GEMOX regimen is comparable to ESHAP regarding RR and PFS. The hematologic toxicity rates were similar in both arms; however, renal toxicity and vomiting were less with GEMOX while neurotoxicity was lower in ESHAP. GEMOX may be considered in frail patients with renal impairment.

\section{Conflict of Interest}

None to declare.

\section{REFERENCES}

1. Friedberg JW. Relapsed/refractory diffuse large b-cell lymphoma. ASH Education Program Book. 2011; 1: 498505.

2. Gisselbrecht C, Glass B, Mounier N, et al. Salvage regimens with autologous transplantation for relapsed large B-cell lymphoma in the rituximab era. J Clin Oncol. 2010; 28(27): 4184-4190.

3. Crump M, Kuruvilla J, Couban S, et al. Randomized comparison of gemcitabine, dexamethasone, and cisplatin versus dexamethasone, cytarabine, and cisplatin chemotherapy before autologous stem-cell transplantation for relapsed and refractory aggressive lymphomas: NCICCTG LY.12. J Clin Oncol. 2014; 32(31): 3490-3496.

4. Aparicio J, Segura A, GarceráS, et al. ESHAP is an active regimen for relapsing Hodgkin's disease. Ann Oncol. 1999; 10(5): 593-595.

5. Labrador J, Cabrero-Calvo M, Pérez-López E, et al. ESHAP as salvage therapy for relapsed or refractory Hodgkin's lymphoma. Ann Hematol. 2014; 93(10): 17451753.

6. Velasquez WS, McLaughlin P, Tucker S, et al. ESHAP-an effective chemotherapy regimen in refractory and relapsing lymphoma: a 4-year follow-up study. J Clin Oncol. 1994; 12(6): 1169-1176.

7. Wang WS, Chiou TJ, Liu JH, et al. ESHAP as salvage therapy for refractory Non-Hodgkin's lymphoma: Taiwan experience. Jpn J Clin Oncol. 1999; 29(1): 33-37.

8. Gutierrez A, Rodriguez J, Martinez-Serra $J$, et al. Gemcitabine and oxaliplatinum: an effective regimen in patients with refractory and relapsing Hodgkin lymphoma. Onco Targets Ther. 2014; 7: 2093-2100.

9. López A, Gutiérrez A, Palacios A, et al. GEMOX-R regimen is a highly effective salvage regimen in patients with refractory/relapsing diffuse large-cell lymphoma: a phase II study. Eur J Haematol. 2008; 80(2): 127-132.

10. Mounier N, El Gnaoui T, Tilly H, et al. Rituximab plus gemcitabine and oxaliplatin in patients with refractory/relapsed diffuse large B-cell lymphoma who are not candidates for high-dose therapy. A phase II Lymphoma Study Association trial. Haematologica. 2013; 98(11): 1726-1731.

11. El Gnaoui T, Dupuis J, Belhadj K, et al. Rituximab, gemcitabine and oxaliplatin: an effective salvage regimen for patients with relapsed or refractory B-cell lymphoma not candidates for high-dose therapy. Ann Oncol. 2007; 18(8): 1363-1368.

12. Corazzelli G, Capobianco G, Arcamone M ,et al. Longterm results of gemcitabine plus oxaliplatin with and without rituximab as salvage treatment for transplantineligible patients with refractory/ relapsing B-cell lymphoma. Cancer Chemother Pharmacol. 2009; 64(5): 907-916.

13. Cheson BD, Fisher RI, Barrington SF, et al. Recommendations for initial evaluation, staging, and response assessment of Hodgkin and non-Hodgkin lymphoma: The Lugano classification. J Clin Oncol. 2014; 32 (27): 3059-3067.

14. International Non-Hodgkin's Lymphoma Prognostic Factors Project. A predictive model for aggressive nonHodgkin's lymphoma. N Engl J Med. 1993; 329(14): 987994.

15. Pfreundschuh M, Kuhnt E, Trümper L, et al. CHOP-like chemotherapy with or without rituximab in young patients with good-prognosis diffuse large-B-cell lymphoma: 6year results of an open-labelrandomised study of the MabThera International Trial (MInT) Group. Lancet Oncol. 2011; 12(11): 1013-1022.

16. Vose JM, Rizzo DJ, Tao-Wu J, et al. Autologous transplantation for diffuse aggressive non-Hodgkin lymphoma in first relapse or second remission. Biol Blood Marrow Transplant. 2004; 10(2): 116-127.

17. Philip T, Guglielmi C, Hagenbeek A, et al. Autologous bone marrow transplantation as compared with salvage chemotherapy in relapses of chemotherapy-sensitive nonHodgkin's lymphoma. N Engl J Med. 1995; 333(23): 1540-1545.

18. Seshadri T, Kuruvilla J, Crump M, et al. Salvage therapy for relapsed/refractory diffuse large B cell lymphoma. Biol Blood Marrow Transplant. 2008; 14(3): 259-267.

19. Gisselbrecht C, Schmitz N, Mounier N, et al. Rituximab maintenance therapy after autologous stem-cell transplantation in patients with relapsed CD20(+) diffuse large B-cell lymphoma: final analysis of the collaborative trial in relapsed aggressive lymphoma. J Clin Oncol. 2012; 30(36): 4462-4469.

20. Prince HM, Imrie K, Crump M, et al. The role of intensive therapy and autologous blood and marrow transplantation for chemotherapy-sensitive relapsed and primary refractory non-Hodgkin's lymphoma: identification of major prognostic groups. Br J Haematol.1996; 92(4): 880889.

21. Hamlin PA, Zelenetz AD, Kewalramani T, et al. Ageadjusted International Prognostic Index predicts autologou s stem transplantationoutcome for patients with relapsed or prima ry refractory diffuse large B-cell lymphoma. Blood. 2003; 102(6): 1989-1996.

22. Conde E, Sierra J, Iriondo A, et al. Prognostic factors in patients who received autologous bone marrow transplantation for non-Hodgkin's lymphoma. Report of 104 patients from the Spanish cooperative Group GEL/TAMO. Bone Marrow Transplant. 1994; 14(2): 279286.

23. Thieblemont C, Briere J, Mounier N, et al. The germinal center/activated B-cell subclassification has a prognostic impact for response to salvage therapy in relapsed refractory diffuse large B-cell lymphoma: A bio-CORAL study. J Clin Oncol. 2011; 29(31): 4079-4087. 